istic". But it argues that the academy, which is still responsible for the operation of a large number of research institutes, "should play a more limited and traditional role similar to that of the Royal Society or other major western academies of science".

The panel members say they decided to endorse requests "expressed by the majority of the scientific community" for a significant increase in government spending on research. They acknowledge the economic difficulties caused by the shift to a market economy. But they warn that, if the budgetary stringency resulting from the current transitional phase is prolonged, "Polish R\&D may well lose its strongest assets".

Finally, the OECD panel is sharply critical of what it describes as the excessive "egalitarianism" that has come to dominate many universities since the fall of communism, arguing that it can lead to a fragmentation of programmes and a dispersal of resources that would be "particularly unfortunate" at a time of growing budgetary restrictions.

It argues, instead, for the concentration of a "substantial proportion" of both human and financial resources in centres of research excellence.

At a press conference held after the Warsaw meeting, Luczak, who took over as chairman of $\mathrm{KBN}$ at the beginning of this year, said that two of the OECD panel's most controversial sets of proposals were those on the future of the academy and on creating a centralized science funding agency comparable, for example, to the Centre Nationale de la Recherche Scientifique in France.

Equally controversial, he said, was the proposal to merge higher education institutions in various cities throughout Poland into "comprehensive universities". The panel suggested, for example, that the decision to integrate a medical academy into the Jagellonian University in Krakow could be copied in other cities.

Czeslaw Strumillo, vice-chairman of the $\mathrm{KBN}$, said that implementing the proposals accepted by the government "would take time". Nevertheless, he described the report as a "rich source of information" that would be of considerable value to the government in formulating its future plans.

\title{
Strong yen prompts Japanese search for overseas talent
}

Tokyo. Under pressure from the rising value of the yen and Japan's prolonged recession, many Japanese companies are reorganizing their research and development (R\&D) efforts both domestically and overseas.

This restructuring appears to be aimed not only at the conventional goal of bringing new products more quickly to market but also at finding ways of tapping into the creative talents of Western researchers to make up for their apparent absence in Japan in areas such as software design.

A survey last month by the Nikkei Shimbun, Japan's leading financial newspaper, of 35 major companies - including electronics, steel, automobile and pharmaceutical manufacturers - revealed that nearly twothirds have reorganized their $\mathrm{R} \& \mathrm{D}$ divisions over the past year or will soon do so.

In addition, more than a third of those covered by the survey reported that they intend to set up new R\&D facilities overseas soon or to strengthen existing ones.

For example, at the end of June, Mitsubishi Electric reorganized its $R \& D$ so that near-market research formerly carried out by various corporate research laboratories will now be done by the business section most closely related to the research.

Specifically, three laboratories, the Computer and Information Systems Laboratory, the Communications Systems Laboratory and the Image Systems Laboratory will be split and merged into two development centres, for information and communication systems and visual information systems, under the corresponding business units.

Eight other laboratories, including the company's central research laboratory near Osaka, will be merged into two centres, the Advanced Technology R\&D Center and the Information Technology R\&D Center.

Similarly, Matsushita Electric last year merged four research laboratories, including its central research laboratory, into a corporate headquarters for research while another five have been combined into a separate headquarters for product development. This followed a reorganization by the rival company Sony in the previous year tying nearmarket research more directly to the 24 business groups that make up the company (Nature, 361, 193; 1993).

In all three cases, the goal of the restructuring has been to strengthen and speed up the introduction of new products to the market in order to help companies pull out of the recession. This contrasts with the so-called 'bubble economy' of the late 1980s, when Japanese companies poured money into new institutes carrying out basic research far from the market.

Such research is now being squeezed. None of the 35 companies surveyed said they expect to increase their support for basic research, although several also said that they do not plan any major reduction in such funding because of the long-term importance of such research.

Partly because of the rapidly rising value of the yen, several companies are planning to set up new research institutes in the United States and Europe. The average salary of a Japanese company researcher is equivalent to the most highly-paid researchers in the West, and Japanese companies are hoping to recruit talented Western researchers to the new laboratories.

But, unlike the institutes set up by Japanese companies in Europe and the United States in the late 1980s - many of which focus on quite basic research - the new facilities will be closer to market. One particular focus will be the development of new multimedia.

In August, Mitsubishi Electric will set up two R\&D units in Europe. One in London will conduct research on digital broadcast technology, and will interact with another in France, focusing on telecommunications.

At the same time, two existing research groups in the United States - one working on high-definition television in New Jersey and another in California developing multimedia - will be brought under the wing of a single unit in Massachusetts, and their personnel will be expanded.

Japan's recent economic success has been built on combining high- quality production technology with mass production techniques. But many of the companies included in the survey said they think that future economic success will rest in the rapid development of software and new ideas - areas in which industrial research in Japan tends to be weak. So an additional incentive for establishing research facilities in the West is to gain access to what are widely seen as the more creative skills of Western researchers. 